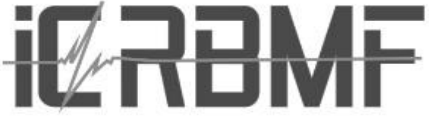

\section{Development of Effective Management Theories}

\author{
Muhammad Asadullah ${ }^{1}$, Syed IRFAN Hyder ${ }^{2}$ \\ ${ }^{1}$ Institute of Business Management, Karachi, Pakistan \\ ${ }^{2}$ Institute of Business Management, Karachi, Pakistan
}

\begin{abstract}
This paper examines how Ghoshal's views (2005) of bad management theories are destroying good management practices. The authors propose a solution through which we may identify the bad management theory at an early stage. The authors posit that the theorist should have intuitive ability which is a pre-requisite to develop an effective theory. As far as intuition is concerned, we cannot test the intuitive ability of any individual, therefore a "think tank" may evaluate a management theory according to ethical and cultural perspective. If a management theory is culturally rich and ethical then it will be universally acceptable. On other hand, if management theory lacks characteristics of being culturally rich or poor ethical values then it should be modified or excluded from the literature. All ethical management theories which may not be culturally rich should be addressed with double hermeneutics according to region.
\end{abstract}

KEYWORDS: ethics, cultural richness, intuitive mindset, management theory and moral values.

\section{Introduction:}

This paper attempts to develop a solution of Ghoshal's earlier article about how bad management theories are destroying good management practices. In that article, the author stated that bad management theories have had a negative effect on our business culture. It has been the dilemma of the corporate sector that despite of regulatory laws, management theories and other protocols, we are still facing the scandals of insider trading, frauds and misconduct by top management, line and staff managers, officers and clerical staff all over the world.

In every sector of society, there is a "think tank" which works for its betterment and for the corporate sector. it is definitely the Business Schools, their respected faculty members, and no doubt the $\mathrm{PhD}$ research students who are the ones who are in the forefront but are they effective? The question is why we are still facing the controversial issues in the corporate world after wasting our energies in preparing corporate laws, designing grounded management theories and emphasizing on organizational behaviors? The first answer came from (Ghoshal, 2005) i.e. The Business schools should stop their traditional thinking pattern and ensure that they play a role to do something effective which will help to avoid such harmful performance in the corporate world. 


\section{iERBMF}

Ghoshal (2005) describes the process that how bad management theories are destroying the good practices. According to him, there are two main factors which lead to the development of bad management theories. First, "The pretense of knowledge", the concept which was originated by Hayek (1989). This concept defines business as a science that is determined by the economic, social and psychological laws that inevitably shape people's actions. Ghoshal argues that this trend takes away ethical or moral debates that may arise when a decision has been made. It is specifically related to the decisions taken by the CEOs. In some situation, CEOs take actions which benefits shareholders but on the other hand, such decision may be unfavorable for the other stakeholders. Actually the CEOs do not take business as "science" and combine information of "what is" with the assumption of "what should to be" to develop corporate an understanding of what actually corporate governance presents.

The second phenomenon was given by Milton Friedman (2002) "Ideology Based Gloomy Vision" quoted as "liberalism". It defines negative assumptions that exist in the management theory therefore managers are unable to play a positive role in society, organization, corporate governance in the corporate world. There is a pessimistic view of human nature, on the roles of companies in society, and of the procedures of corporate adaptation and modification. Such pessimistic of managers leads to the destruction of management practices. In order to avoid pessimistic behavior, the theorist should provide clear insight for the future managers rather than a gloomy vision where they could not judge the right direction. Ghoshal (2005) further validates that there should be prerequisites of developing a new theory. i.e. morality and ethics. Overall, the process of Ghoshal's Bad theories destroying Good practice is shown below in Figure 


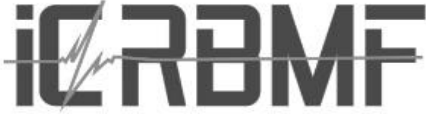

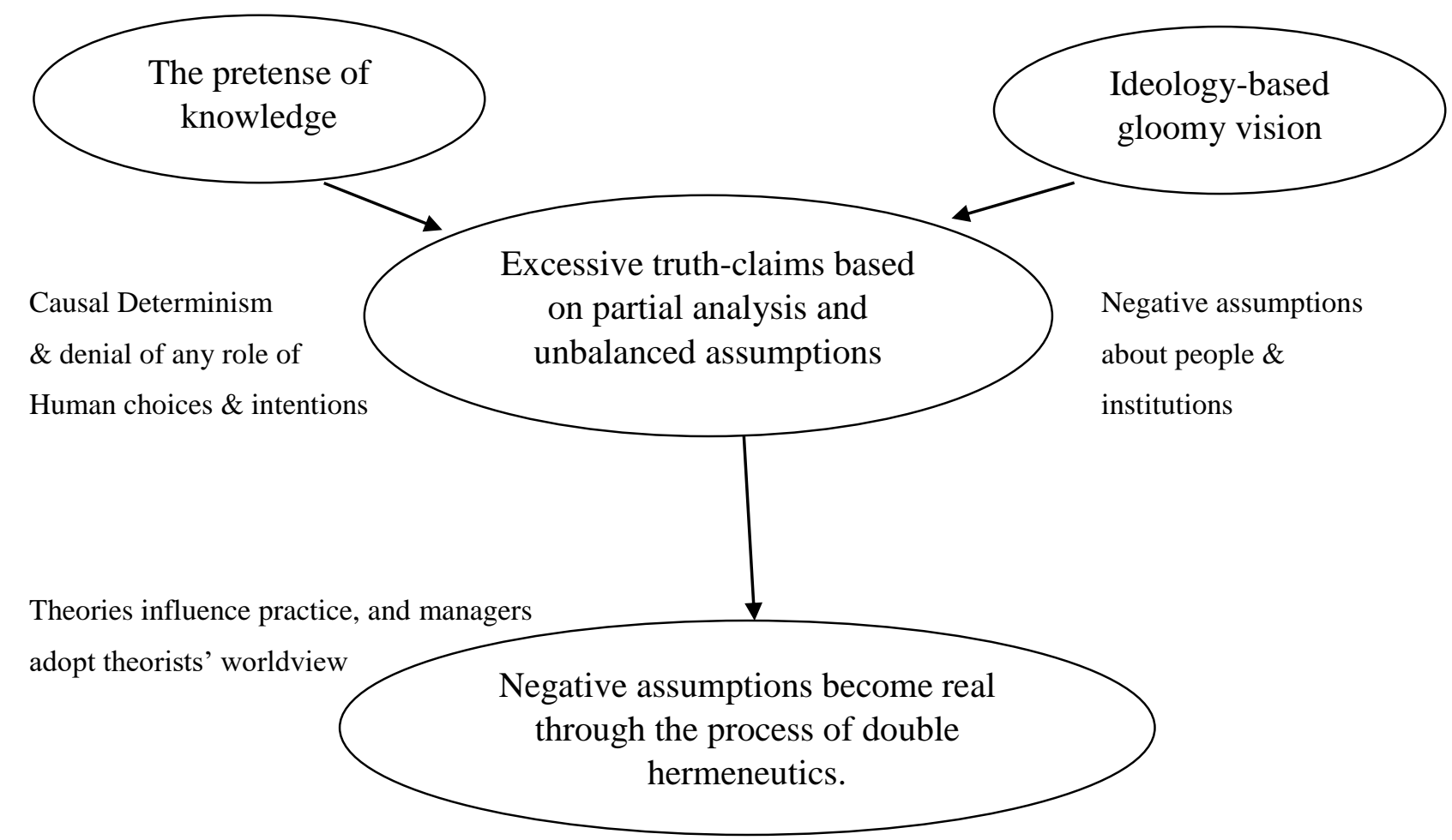

FIGURE 1

The Process of Bad Theories Destroying Good Practice

Source: Ghoshal (2005)

\subsection{Discrepancies in Different Management Theories:}

Douglas et al (2016) argued that CEOs and Boards of Director have been engaging in creating losses for the societies because of their self-interest motives for the organization. It was concluded by the author to bound the assumptions of self-interest with the norms of fairness and parsimonious reciprocity. Dumtiru et al (2015) pointed out that there is no policy which control or monitor the managers by shareholders of the company, therefore, probability of conflict of interest increases. On the other hand, the author believed that it is not possible to implement universal policies of controlling in all organizations, therefore, policies should be generated according to the environment in which firms operate.

J. Hall (1998) recommended that the conflict of interest should be addressed and raised by the shareholders by high voting percentage in the Annual General Meeting of the company. The author also proposed this characteristic as the part of Agency Theory to secure the interest of shareholder. In another paper written by Luh Luh Lan (2010), the author redefined the principles 
of three parties i.e. Board of directors, shareholders and agents. According to the author, if such principal will be implement with agency theory then conflict of interest will not take place.

Ghoshal (1996) argued that in Transaction Cost Economics theory, there is actually wrong assumption and logic about the organization and market therefore misconception arise. The author recommended that now scholars should focus on organizational economy rather than market economy in order to avoid such misconceptions in future.

Mikko et al (2016) further demonstrated that Transaction Cost Economics Theory is actually a constructive stakeholder theory which provides the basis for the stakeholders of the company. Ander el (2008) criticized the stakeholder theory and stated that there are unbalanced assumptions regarding motives of managers. Moreover, the ethical and moral view of the theory are missing.

Table 1: Summary of Discrepancies in Different Management Theories.

\begin{tabular}{|c|c|}
\hline Discrepancies & Findings \\
\hline \multicolumn{2}{|l|}{ Agency Theory: } \\
\hline CEOs and boards create losses for society. & $\begin{array}{l}\text { Assumptions of self-interest bound by norms of parsimonious } \\
\text { reciprocity and fairness. }{ }^{1}\end{array}$ \\
\hline CEOs and boards create losses for society. & $\begin{array}{l}\text { Assumptions of self-interest bound by norms of parsimonious } \\
\text { reciprocity and fairness. }{ }^{1}\end{array}$ \\
\hline $\begin{array}{l}\text { Policies of monitoring and controlling of } \\
\text { managers by shareholders is missing. }\end{array}$ & $\begin{array}{l}\text { Proper \& individual environment, analysis in which the firm } \\
\text { operates, is needed. }{ }^{2}\end{array}$ \\
\hline Conflict of Interest & Address by high voting percentage. ${ }^{3}$ \\
\hline Conflict of Interest & Redefine the principals of three parties by view of law ${ }^{4}$. \\
\hline \multicolumn{2}{|l|}{ Stakeholder Theory: } \\
\hline Conflict of Interest & $\begin{array}{l}\text { Unbalanced Assumptions about manager motives \& lack of } \\
\text { discourse on issues related to ethics and morality }{ }^{5} \text {. }\end{array}$ \\
\hline \multicolumn{2}{|l|}{ Transaction Cost Economics Theory: } \\
\hline $\begin{array}{l}\text { Wrong Assumptions \& Logic Of TCE regarding } \\
\text { market and organization. }\end{array}$ & $\begin{array}{l}\text { Instead of developing theory on market economy, emphasize } \\
\text { on organizational economy }{ }^{6} \text {. }\end{array}$ \\
\hline Wrong perception & $\begin{array}{l}\text { It is also consistent with the stakeholder theory and can be } \\
\text { apply as constructive stakeholder theory }{ }^{7} \text {. }\end{array}$ \\
\hline Conflict of Interest & Address by high voting percentage. ${ }^{3}$ \\
\hline
\end{tabular}

Ghoshal (2005) stated that the main issue in our management theories is the absence of ethical and moral values. Furthermore, Ghoshal (2005) stated that the theorist emphasizes more on negative problems and overlooks positive problems. The purpose of development of theories is being misunderstood by the theorist. Jeffrey (2005). Now, it is the high time that Business schools should challenge such claims rather than simply accept them and deliver in classes. 


\section{iEREMF}

Table 2: Opinion and Views About Why Management Theories Fail? \& Their Remedies.

\begin{tabular}{|c|c|}
\hline Reasons of Management Theories Failure: & Remedies \\
\hline Emphasize on solving only "negative" problems. ${ }^{1}$ & $\begin{array}{l}\text { Business Schools Should be challenging rather than } \\
\text { commanding } 1\end{array}$ \\
\hline 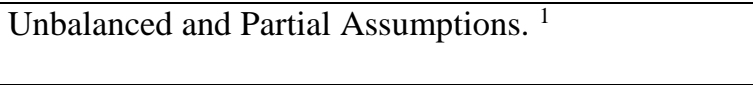 & $\begin{array}{l}\text { Theorist should be centered both on "negative" and } \\
\text { "positive" problems } 1\end{array}$ \\
\hline Lack of ethics and morality. ${ }^{1}$ & Integration of ethics and morality ${ }^{1}$. \\
\hline Unintentionally accept the bad theory as "TRUE". ${ }^{1,2}$ & Reluctant in Acceptance of Claim Truth ${ }^{\mathbf{1 , 2}}$ \\
\hline
\end{tabular}

\section{PROBLEM STATEMENT:}

The unbalanced assumptions and partial analysis lead to the failure of management theories and systems.

2.1 Unbalanced Assumptions: For the purpose of development of management theory, the unbalanced assumptions can be defined as the unrealistic or biased assumptions. It is irrelevant that such unbalanced assumptions were generated by the theorists intentionally or unintentionally.

2.2 Partial Analysis: According to Ghoshal (2005), some management theories are accepted as truth by the author, teachers and business students before complete empirical analysis or application of such management theories in the business world. The lack of comprehensive empirical analysis before or after implementation of such management theories in the corporate world is the "Partial Analysis".

This problem may be addressed by inducting a pre-requisite framework which will analyze the management theory from different perspectives. Business schools should not teach any management theory straight away in the class. The author gives an attempt to provide a framework through which Business Schools evaluate the management theory themselves. Such evaluation will provide an opinion whether this theory should be adopted in our classrooms straight away, with modifications or exclude it from course outlines.

\section{METHODOLOGY:}

The philosophical inquiry will be conducted to find out the solution of research problem. Moreover, there are different types of philosophical inquiry methodologies i.e. Logic, Argument and Dialectic, therefore, according to the nature of philosophical inquiry, the methodology of Argument will be incorporated in this study. The methodology of "Argument" can be defined as the author provide arguments or several arguments in order to support the propose solution. Such arguments can also be supported by previous literature findings.

\section{HOW WE CAN SOLVE THIS PROBLEM?}

The researcher gives an attempt to find out the solution of how to develop an effective theory and how to prevent the managers to apply any bad management theory which will lead to the destruction of management practices. The author formulates the below process for this purpose. 


\section{iER日MF}

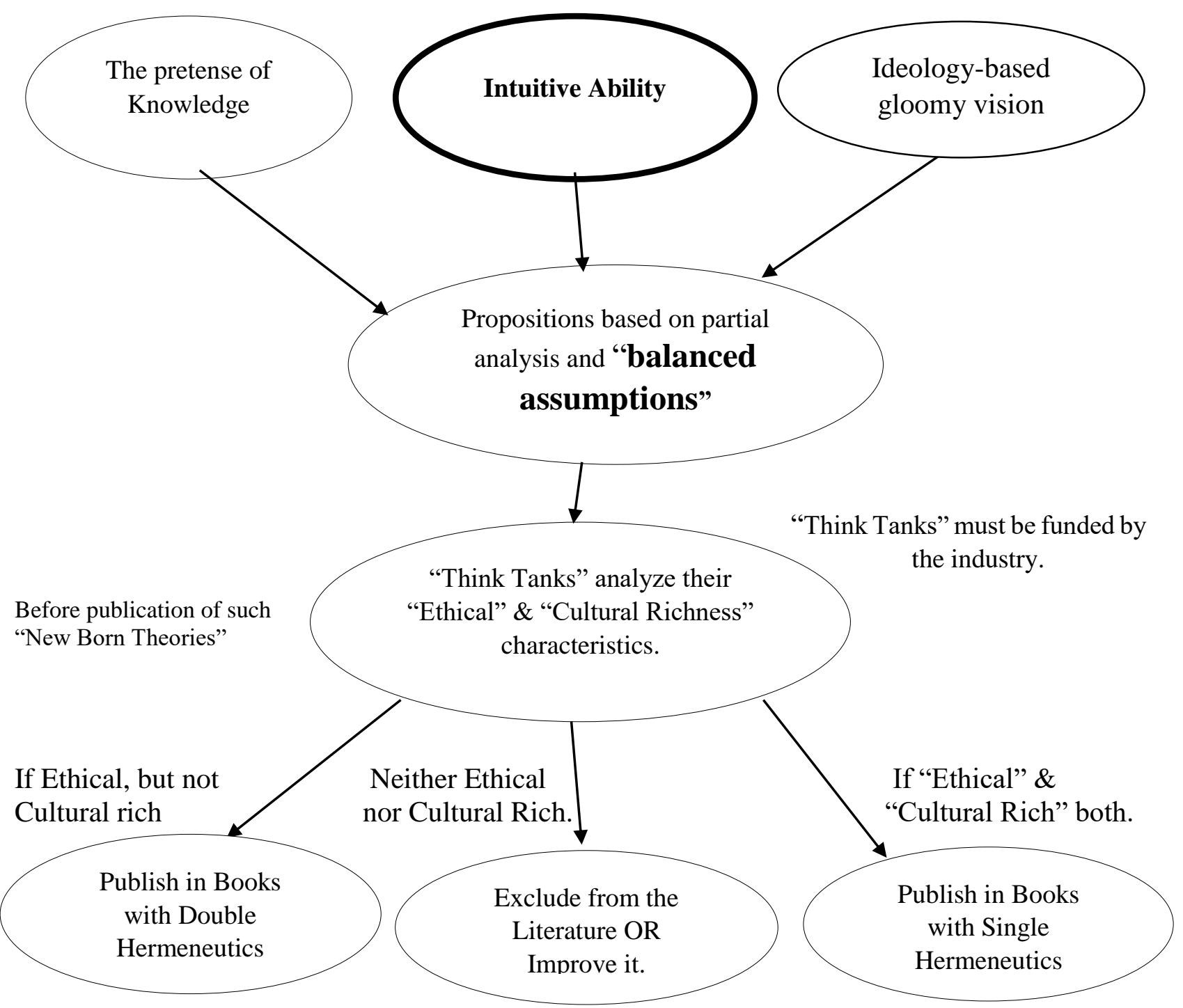

Figure\#2

Proposed Roadmap to Develop an Effective Theory for Future Managers.

Source: Incorporated by Authors 


\section{iE}

\subsection{Intuitive Mindset:}

Being a part of the corporate world "think tank", it is the duty of all current scholars, senior faculty members and researchers to design an efficient roadmap which will lead towards efficient theory development process. The pedagogy should not be tilted towards managers and organizations only, but also include stockholders or shareholders and their interests as well. In the twenty first century, the most important model which should be incorporated into corporate culture is "Intuition". Cinla Akinci et al (2012) explained intuition, not as a mysterious or mystical process, but as a necessary cognitive model for the knowledge worker.

Peter Drucker (1959) analyzed how scientific research techniques joined with business concerns about latest development in technology and invention, he uncovered how the "intuitive manager" became an idealistic case of ruling in a knowledge economy. With the help of "intuition", the researcher could easily diagnose the future problem and issues which will lead to develop the valid assumptions while developing a grounded theory in management. Once again, it depends on the ability of the researcher that how one thinks about the current and future dilemmas of the management practices. Cinla Akinci et al (2012) answer one of the reasons of bad theory development in management by quoting:

"Until the turn of the century, developments of note in intuition research occurred mainly outside the fields of management. Within management research the picture was sometimes confused and contradictory".

In Ghoshal's process, the issues of partial and unbalanced assumptions are the reasons of lack of intuition to some extent. But the questions relevant to intuition are as below:

(a) Who are the people having effective intuition?

(b) Do researchers acquire such ability?

(c) Do Business schools recognize those faculty members whom having effective and efficient intuition ability?

To be honest, the full answers of the above questions are not available as yet, but researchers answer them in different ways. From the perspective of 'intuition-as-expertise' (Sadler-Smith and Shefy, 2004) informed intuition is the result of extensive and deliberate practice, reflection, feedback, and analysis (Dreyfus and Dreyfus, 1986) So, according to some of the researchers, it enhances with an increase in experience in the industry and simultaneously the knowledge which one acquired during the tenure of gaining experience. On the other hand, some experts described other ways to develop or recognize the ability of intuition within one's mindset. Kahneman and Klein (2009) mapped the boundary conditions that separate intuitive expertise from overconfident and biased judgments. It is a very important statement by Kahneman et al (2009) because an individual should know and distinguish between the ability of intuition or being over-confident because of their self-esteem position. The self-esteem position may accept the fact that they are more superior than others which will lead to a frenzy of thoughts but useless due to over confidence. 


\section{iERBMF}

\subsection{Ethics:}

One of the arguments, which Ghoshal (2005) has addressed in his paper, was ethics and moral values, which he felt were absent in management theories or excluded by the researchers. Therefore, managers and employees choose "opportunistic behavior" which will hurt the organization structure and performance. Morality and ethics should have a pre-determined framework which should be followed by the researcher before or during theory developing stage. For this purpose, as Ghoshal discussed, business schools should move forward and more towards ethical and moral framework for future researchers. It may lead towards the satisfaction of all individuals, including managers, shareholders, stakeholders and the organization itself.

To reconcile the gap of ethics, the "think tank" should take another step towards the analysis of ethical perceptions in the provided theory before delivering to their students. It is now the most important and crucial pre-requisite to evaluate every theory according to ethics and morality framework. If it fits, then go with it otherwise just drop it before it reaches the learning platform. If we fail to do so, then it will work as a "slow poison" for the global economy. In the end, we will see more future "Enrons" or may be another global financial crisis. Such consequences may lead to the destruction of the economic system, increase in unemployment and loss of business opportunities and investments. Domenec Mele (2007) wrote about the symposium in which the theme was about the more comprehensive integration of ethics into management held in IESE Business School in May, 2006. He demonstrated the performance of task force that "on the premise that the crisis in business ethics not only is a challenge for companies but also an opportunity to strengthen management education".

In this symposium, the faculty members are not satisfied about the pedagogy of teaching ethics in management. It is strange that we are teaching separate courses of Ethics for Business management students but on the other hand, they are learning unethical management theories.

\section{(i) How to evaluate the ethics in Management Theory?}

Now the question is what should be the evaluation criteria of gauging the ethical existence in the proposed theory'. So far, we do not have any full-fledged ethical evaluation system through which we can judge the existence or absence of ethical substance in the literature. In this study, the author has proposed an ethical framework which should be followed by the theorists and Business schools to examine the ethical perception of the thesis. The standard of the ethical framework is to spread happiness to greater numbers rather than individuals within moral ethical limitations. Table 1 illustrates the ethical requirement for a theory as below:

Table 4: Ethical Requirement for the Theorists

\begin{tabular}{|c|c|c|c|c|}
\hline \multicolumn{2}{|c|}{ Non-Consequentialism } & \multicolumn{3}{|c|}{ Consequentialism } \\
\hline $\begin{array}{c}\text { Deontology } \\
\text { (Kant) }\end{array}$ & $\begin{array}{c}\text { Virtue } \\
\text { (Aristotle) }\end{array}$ & $\begin{array}{c}\text { Utilitarianism } \\
\text { (Jeremy Bentham and } \\
\text { John Stuart Mill) }\end{array}$ & $\begin{array}{c}\text { Egoism } \\
\text { (Sidgwick, } \\
\text { Henry) }\end{array}$ & $\begin{array}{c}\text { Hedonism } \\
\text { (Arristipus) }\end{array}$ \\
\hline - & $\checkmark$ & $\checkmark$ & - & $?$ \\
\hline
\end{tabular}




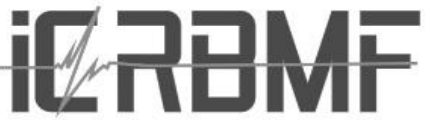

Table 4 illustrates the most important theories of ethics. It is an attempt to understand and design the ethical pre-requisite for any management theory which will play a valuable role for the whole economy. The researcher has tried to include such ethical perceptions which emphasize on pluralism rather than individualism. In Non-Consequentialism, there are two main theories i.e. Deontology by Kant and Aristotle's Virtue. In Consequentialism, three most important theories are selected i.e. Utilitarianism, Egoism and Hedonism.

\section{(a) Deontology:}

Kant (1964) defined deontology as the check whether the individual is consistent in his duties or not. It totally ignored the consequences of certain act, which must be fulfilled by that individual. According to my point of view, the existence of deontology in any theory should not be mandatory as it is very rare that one has to perform some act forcibly which will lead towards damage. For the betterment of new world, the theories should be aligned towards great number of people and their benefits. For me, deontology should be avoided and if it exists in any theory then the "think tank" should look into the "enforceable duties" of that person and its consequences. Deontology should not be the major requirement for the formulation of any management theory because managers are not working for themselves only, they have to work for the prosperity of the company and its shareholders as well.

\section{(b) Virtue:}

Aristotle has defined the eighteen virtues in his book that enable an individual to perform his function effectively and efficiently within moral values. If management theory is proposed by the theorist, then "think tank" must test the intrinsic and extrinsic virtues within the context. If such virtues are available, then definitely the consequences will be favorable. In management theory literature, for the improvement of management practices, the virtue ethics defined by Aristotle should be mandatory as it will be helpful to integrate the ethical and morality aspects with management practices which was argued by Ghoshal (2005). In addition, virtue should be distinguished from deontology as deontology is an "enforceable" job irrespective of consequences but virtue is not.

\section{(c) Utilitarianism:}

Utilitarianism was originated by Jeremy Bentham and John Stuart Mill (1789), It identifies the good with pleasure, so were hedonists about value. For the management theories, the consequences matter as it affects the internal and external business environment which sometimes may lead to a global crisis. It is the requirement of todays' corporate world to implement such practices which will result in aggregate benefit rather than a small minority. If virtue and utilitarianism exist, then the issue of ethics and morality in management would be largely resolved.

\section{(d) Egoism:}

Sidgwick (1907) claims that each soul possesses only one ultimate aim: its own benefit. Normative forms of egoism make claims about what any individual should do rather than what they are actually doing. Ethical egoism claims an action to be morally right if it maximizes one's self-interest. Rational egoism claims that for the purpose of maximizing self-interest, the act must be rational. According to management theory, the literature that emphasizes selfishness will be 


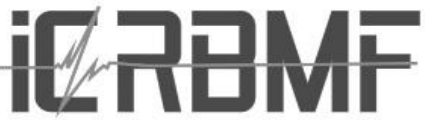

dangerous rather than any propositions that engaged beyond the self- interest. The issue in the corporate world is the individualism rather than pluralism. The competition has killed a number of firms which create unemployment and created other problems as well. If any individual will work without any code of conduct only for self-interest, then how it could be ethical? For the betterment of the business world, we have to move forward with effective competition rather than destructive approach. The ethical theory of egoism will definitely hurt the management practices therefore I would recommend that if any management theory is based on "individualism" or "self-interest" then it should be avoided.

\section{(e) Hedonism:}

Jeremy Bentham (1789) asserted both psychological and ethical hedonism as "Nature has placed mankind under the governance of two sovereign masters, pain and pleasure. It is for them alone to point out what we ought to do, as well as to determine what we shall do". In Hedonism, there is a lack of justification for measuring of intrinsic happiness and sadness which requires serious attention of philosophers to assert the phenomenon. In management theories, the existence of hedonism is unanswerable as we do not know where the shareholder will spend his profit? Whether he might live a rational life and increase his standard of living with an increase in purchasing power or he may waste his money in bars, indulge in gambling, etc. Similarly, we do not know that how society will react if the firms' revenues are declining and salaries become accrued. Either the society will play a constructive role or initiate the protest against government. The integration of hedonism in management theories can't be answered until we could calculate the intrinsic happiness or sadness of the society.

All in all, there are some ethical theories which satisfy the individual satisfaction or for their betterment whereas other ethical theories emphasize on overall benefit for the greater number of people, therefore, according to authors point of view the collective benefit characteristics of ethical theories should be integrated in the management theories. If any management theory lacks the features of collective benefits, then the self -interest phenomenon will destroy the good management practices.

\subsection{Culture Diversion Effects:}

Geert Hofstede (1993) stated that Management scientists, writers and theorists are human. They grew up in a specific society in a certain period, and their ideas cannot help but reflect the constraints of their environment. According to me, the argument is very clear and concrete because there are a number of theories which are well practiced in one society but not in the other one due to demographical representation, work environment, business structure, cultural norms, diversification etc. It can be argued that the management practices mainly depend on the economic situation and education system of country. Yes, the education system differs from North America to Europe and from Europe to the Middle East and from the Middle East to Africa or South Asia. The needed argument is that management theory should be culturally rich and diversified. If not, then constraint it to that specific region only otherwise it will be one of the major drawbacks for global managers. I would shun such theories which are not culturally rich and diversified because the managers of multinationals will move in different directions if they come in from different regions. It should be the pre-requisite for all Business schools to evaluate all theories as "culturally rich" before allowing them on the teaching pedagogy. 


\section{iERBMF}

\section{(i) How to examine the cultural effect in Management Theory?}

This is the million-dollar question which was answered by Geert Hofstede (1993). He stated that there are five dimensions which define the management and social culture of specific country. Management theories are not universally acceptable because of these dimensions and that is why it is one of the main reasons of failure of good management practices across the globe. The five dimensions are power distance, individualism, masculinity, uncertainty avoidance and students' values'. He further demonstrated that the first four dimensions described forty-nine percent of the variance while remaining fifty-one percent variance remain specific to individual countries. I would personally prefer the first four dimensions to check the cultural effect of any management theory because students' values' is itself very broad phenomenon and due to increase in acquiring partial qualification from home country and remaining from abroad, one could not gauge their values effectively. Let's have a look at the four main dimensions.

\section{(a) Power Distance:}

Geert Hofstede (1993) defined the power distance as the "degree of inequality" among people who consider the population as normal. The degree of inequality may differ from country to country. In Europe \& North America, it may be almost identical but it has greater variation in other regions like the Middle East, South Asia, etc. If the origin of any management theory is Europe, then it is the duty of "think tank" to evaluate the impact of power distance on such theory. It would be helpful to understand its applicability and universality. Moreover, the theory having different power distance phenomenon should be delivered with such information.

\section{(b) Individualism:}

It is the degree to which people of a country prefer to act individually rather than as a team. The countries where individualism is more prominent may discourage collectivism. In some countries collectivism may be the standard not individualism. Think tank should test the management theories in such a way to see if they prefer individualism or collectivism to find out that where such theories will be appropriate and where not.

\section{(c) Masculinity:}

It is the degree to which tough values like assertiveness, performance, success and attention are associated with the role of men, whereas maintaining warm service relationship, care, services and solidarity are associated with the role of women, with tough societies. The role of men and women may differ from country to country and from region to region. If any management theory is born in a tough society, then think tank must evaluate the effect of such theories in non-tough societies. Similarly, the management theories which originated from non-tough societies are whether appropriate for tough societies or not?

\section{(d) Uncertainty Avoidance:}

It is the degree to which people in a country prefer structured or unstructured situations. Structured situations can be defined as the system, where the rules and mode of behaviors are clear. They are written and sometimes not written, but traditional norms. However, in unstructured situations, the scenario is opposite. Again, the think tank evaluates the impact of uncertainty 


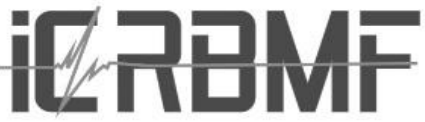

avoidance on management theories and concludes which theories are homogeneously acceptable in both situations and which are not?

The reason of including management theories of Hofstede (1993) and Peter Drucker (1959) is the reliability and validity of their opinions. Even in twenty first century, the prominent issues of management may be rectifying by integrating the management and philosophical point of view of the both researchers. Till now, none of any researcher has rejected their management theories therefore the authors feel that it would be beneficial to include their valuable thoughts in order to solve recent management practices issue due to bad management theories.

\subsection{Business Schools Should Be Funded by The Industry:}

Lastly, Business schools should be funded by the Industry and the corporate world because Business schools will be looking for effective managers not for themselves, but for the corporate world, therefore, it should be the responsibility of industry and corporate world to seriously think about the dilemma of the flood of ineffective managers due to bad management theories. Their funding will be fruitful in the sense that an effective manager will be integrated as a catalyst for any company to generate revenue efficiently rather than a manager who learned bad management theories and destroyed good management practices. If still the corporate world does not understand the importance of such issues, then definitely we may see future "Enrons" in the corporate world. If due to funding, Business schools will may enable to establish an effective "Think Tank" then most probably the production of ineffective product will be declined and that's the another aim of this paper to promote the mutual collaboration among Business schools and the corporate world to understand their concerns altogether and try to find out the solutions for the betterment of each other.

I strongly recommend that top Business Schools should come forward and formulate a group or association to examine the management theories. The leading and experienced faculty members and researchers of top Business schools should work together and work as a single unit "Think Tank". The validity and reliability regarding management theories will be more acceptable in case of working as a single unit. As far as funding concern, we believe that industry will trust One-Unit "Think Tank" more and it will lead to fruitful funding.

\section{CONCLUSION:}

Number of philosophers, theorists and critical analyst have been embedded the thought of an effective process to develop a productive management theory for the global world from number of years but still we do not possess any dominant criteria of evaluating and formatting the proposed management theories. This is the reason of poor management practices as Ghoshal (2005) argued in his article. In this paper, I have tried the two ways, check process, which will enable the theorists themselves and the "think tank" to check the "universality" of the proposed management theory. Globally, we have different foods, cultures, norms, traditions, languages, even behaviors so why not theories? Now, it is the right time to discriminate the management theories according to their cultural and ethical background rather than to impose it globally because it may fail in some regions due to lack of "cultural richness" and "ethical" pre-requisites of that society.

How the two check works in the proposed model? First, Intuitive mindset- everyone need to be sharp, critical thinker and the master of the six sense if they want to be the theorists. If anyone has intuitive ability, then the theorist most probably gauges and forecasts the future events and 


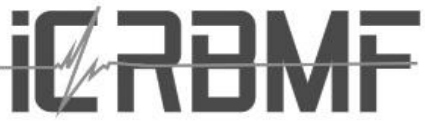

economic transactions. It will enable them to develop balanced assumptions rather than unbalanced assumptions. The loopholes of the combination of "The pretense of knowledge" \& "The ideology based Gloomy Vision" will be minimized by the induction of intuitive skills. It is still questionable that how to evaluate and find out the intuitive skill holders? That is why the second check is being placed by the author to examined every proposed theory before let them publish in the reference books. The second check will be run by the "Business Schools". The authors give an attempt to establish a model to check the ethical and cultural characteristics of the proposed management theory.

The Business Schools will evaluate the management theories from ethical and cultural point of view. First, it will be examined by the think tank that whether management theory contains such ethical norms, which will benefit number of people rather than individual, or not. Secondly, it will be investigated that whether propose management theory contains all aspects of cultural richness or not. If it possesses such attributes which do not discriminate them from other societies then it should be universally acceptable otherwise it would be deliver with different hermeneutics region wise.

The most crucial step toward the betterment of corporate world is to fund the "Business schools" by the corporate world to save them in future from ineffective managers. It could empower the Business school to perform as an active think tank as they will have more funds to spend on researchers to conclude the theory's characteristics. We have already faced so many issues, crisis and discrepancies in the business that's why it is the final time for everyone to create an impact otherwise it will be too late.

It is the author's thought that if such evaluation techniques will be followed by the Business schools then we will have produced more quality managers ever. This process will enable the academicians to prevent the publication of such theories which are useless as they do not have any ethical or culturally rich and if they publish in any book somehow, then professors and other faculty members will teach them according to different pedagogy as these theories will have different implications in different situations. The author has also opened the door for future researchers and critical analyst to provide their judgement in accordance to build an effective system which will postmortem the theory before it will worsen the performance of our managers.

\section{References}

Andre O.L, Karan, S. \& Reginald A. Litz (2008), Stakeholder Theory: Reviewing a Theory That Moves Us, Journal of Management, Vol. 34, No. 6, 1152-1189

Aristotle (1791), Nicomachean Ethics, Book II

Bentham, Jeremy, (1789) An Introduction to the Principles of Morals and Legislation., Oxford: Clarendon Press, 1907.

Cinla. A. and Eugene S.S (2012), Intuition in Management Research: A Historical Review, International Journal of Management Reviews 14, no. 1 -114.

David. T, David. D. \& Palminder. S (2003), Towards a Methodology for Developing EvidenceInformed Management by Means of Systematic Review, British Journal of Management, Vol. 14, 217-222. 


\section{iEREMF}

Dreyfus, H.L. and Dreyfus, S.E. (1986). Mind Over Machine: The Power of Human Intuitive Expertise in the Era of the Computer, New York: Free Press.

Domenec Mele (2007), Integrating Ethics into Management; Journal of Business Ethics, 78:291-297

Douglas. A. B \& Robert. A. P (2016), Agency Theory and Bound Self-Interest, Academy of Management Review, Vol. 41, No.2, 276-297.

Dumitru. N. C (2015), Monitor \& Control in Companies: An Agency Theory Approach, Journal of Public Administration, Finance and Law, Special Issue 2/2015, 46-60.

Elster. J. (1983), Explaining technical change. Cambridge England. Cambridge University Press. E.T. (2007). The making of an expert. 44 Harvard Business Review, July-August, pp. 115-121.

Friedman. M. (2002), Capitalism \& Freedom, (40 ${ }^{\text {th }}$ Anniversary Edition) Chicago. The University of Chicago Press.

Ghoshal. S. (2005), Bad Management Theories Are Destroying Good Management Practices, Academy of Management Learning and Education, 2005, Vol. 4. No.1,75-91.

Hall. J.J (1998), The Agency Problem, Agency Cost and Proposed Solutions Thereto: A South African Perspective, Meditari Accountancy Journal, Vol 6. 145-161

Hayek. F. A. Von. (1989), The pretence of knowledge, Nobel Lecture; American Economic Review; December 3-7.

Hofstede, G. (1993). Cultural Constraints in Management Theories. Academy of Management The Executive, 7(1), 81-94.

Jeffrey Pfeffer (2005), Why Do Bad Management Theories Persist? A Comment on Ghoshal, Academy of Management Learning and Education, Vol 4, No.1, 96-100

Kahneman, D. and Klein, G. (2009). Conditions for intuitive expertise: A failure to disagree. The American Psychologist, 64 (6), pp.515-526.

Kant, Immanuel (1964). Groundwork of the Metaphysic of Morals. Harper and Row Publishers, Inc. ISBN 978-0-06-131159-8.

Luh. L.L (2010), Rethinking Agency Theory: The View from Law, Academy of Management Review, Vol. 35, No.2, 294-314

Mikko. K \& Joseph. T. M (2016), Transaction Cost Economics as A Constructive Stakeholder Theory, Academy of Management Learning and Education, Vol. 15, No.1, 123-138

Peter Drucker coined the term "knowledge worker" to refer to workers who dealt in manipulation of symbols and ideas. Drucker, Landmarks of Tomorrow (New York, 1959).

Sadler-Smith, E. and Shefy, E. (2004). The intuitive executive: Understanding and applying 'gut feel' indecision-making. Academy of Management Executive, 18 (4), pp. 76-91.

Sidgwick, H., (1907), The Methods of Ethics, Indianapolis: Hackett, seventh edition, 1981, I-IV. 